\title{
Norske NS-leger og deres forhold til eutanasi
}

\author{
I det nasjonalsosialistiske Tyskland ble rundt 300000 kronisk syke psykiatriske pasienter og mentalt retar- \\ derte barn drept under et eutanasiprogram som tyske helsearbeidere initierte. I Norge foreslo fremtredende \\ medlemmer av Nasjonal Samling (NS) at tilsvarende avliving av pasienter burde startes. Enkelte NS-leger \\ støttet forslaget, og Medisinaldirektoratets holdning var uklar. Noe offisielt forslag om å innføre pasientdrap \\ ble likevel aldri fremsatt. Mye kan tyde på at profilerte NS-leger stoppet det.
}

Ragnar Stien

ragnarstien@hotmail.com

I en ytring i Tidsskriftet i anledning av at Hedmark Høyre i 2009 hadde foreslått å legalisere aktiv dødshjelp (eutanasi), skriver biskop i Oslo katolske bispedømme Bernt Eidsvig: «Uhyrlighetene ble også forsøkt innført i Norge ved opprettelsen av Quisling-regimets nye helseavdeling i 1941, hvor man i Hoche og Bindings ånd søkte «avlivning av uhelbredelige sinnssyke fra en håpløs og meningsløs tilværelse»»» (1). Er biskopens påstand helt korrekt?

Herrene Eidsvig henviser til, Karl Binding og Alfred Hoche, innførte begrepet «lebensunwertes Leben» og ga et teoretisk grunnlag for det tyske naziregimets systematiske utrydding av kronisk syke psykiatriske pasienter og mentalt retarderte eller «alvorlig vanskapte» barn (2). Dette skjedde under «Aktion T4», benevnt slik fordi hovedkvarteret lå i Tiergartenstrasse 4 i Berlin.

Alle leger i det offentlige tyske helsevesenet var forpliktet til å registrere slike pasienter på egne skjemaer. Bedømt ut fra disse opplysningene ble et stort antall pasienter sendt til 5-6 avlivningsinstitusjoner. Avlivning med giftgass ble her utviklet før de kjente gasskamrene i konsentrasjonsleirene. Andre metoder ble også brukt, slik som injeksjoner av dødelige medikamenter og ren utsulting.

Dette programmet var i virksomhet fra 1939 til slutten av 1941. Store protester, ikke minst fra den katolske kirke, førte til at myrderiene offisielt ble avsluttet, men helseinstitusjonene fortsatte å drepe psykiatriske pasienter og retarderte barn helt til etter krigens slutt i mai 1945 (3). I alt regner man med at ca. 300000 pasienter ble drept i Tyskland (4).

For en lege er det mest skremmende ved dette at drapene på pasienter ble foreslått og gjennomført av leger og annet helsepersonell. Det var ikke det tyske nazipartiet (Nationalsozialistische Deutsche
Arbeiterpartei, NSDAP) som sådant som tok initiativet til «Aktion T4», det var fremtredende tyske leger som foreslo dette. Hitler avblåste offisielt aktivitetene, men helsepersonellet fortsatte uten formell politisk dekning (3). Legene var den akademiske gruppe som i størst grad sluttet opp om nasjonalsosialismen, i enkelte deler av Tyskland var $60-75 \%$ av legene medlemmer i NSDAP (3).

I de områdene av Øst-Europa som Tyskland okkuperte, ble også de samme gruppene utryddet - her uten de formelle prosedyrene og uten falske dødsattester og kondolansebrev til de pårørende når deres nærmeste var død av «slag» eller «lungebetennelse». I Øst-Europa bar drapene mer preg av etnisk rensing av i alle fall antatte «undermennesker» (4). I Frankrike ble mer enn 40000 psykiatriske pasienter sultet i hjel. Dette skjedde i de Vichy-kontrollerte områdene - uten noe pålegg fra myndighetene. Det hele ble ganske enkelt drevet gjennom av helsepersonellet selv (5).

\section{Hva skjedde i Norge?}

Forsøkte så okkupasjonsmakten i perioden 1940-45 å tvinge de norske helsemyndighetene til å innføre tilsvarende eutanasiprogrammer? Tyskerne kunne sikkert tenkt seg slike ordninger, noe en episode referert av sykehusrådmann Thorvald Klaveness (1883-1963) kunne antyde (6). Sjefen for helseavdelingen i Reichskommissariat, Generalstabsartzt Fritz Paris, inspiserte Dikemark sykehus og spurte da direktør Rolv Gjessing (1887-1959) om man hadde begynt å gi pasientene «eine kleine Spritze». Da Gjessing senere spurte Paris om hvordan det sto til med de psykiatriske pasientene i Tyskland, svarte denne «Gibt's keine mehr!» (6).

Prøvde så Medisinaldirektoratet selv å innføre «avlivning av uhelbredelige sinnssyke», slik biskop Bernt Eidsvig hevder? Den nazistiske medisinaldirektøren fra høsten 1940 til mai 1945 var spesialist i nevrologi Thorleif Dahm Østrem (1892-1980). Han var en av sju norske leger som var medlem av Nasjonal Samling fra partiet ble stiftet i 1933. Han ga uttrykk for klare antisemittiske standpunkter, var en lojal tilhenger av Quisling og skrev apologetiske artikler om Føreren, selv lenge etter krigens slutt (7). I forbindelse med arbeidet med norsk nevrologis historie (8) har jeg hatt tilgang til mye arkivmateriale i Riksarkivet med tilknytning til Østrem $(7,9,10)$. Der finnes ingen antydning om at Medisinaldirektoratet i Østrems tid foreslo innført et T4-liknende program i Norge. Heller ikke i det omfattende materiale som hans landssvikdom inneholder, finnes slike antydninger (10). Han ble heller ikke siktet for slike forhold.

\section{Ble arkivmateriale fjernet?}

Helt sikre på medisinaldirektørens holdninger her kan vi likevel ikke være. Problemet er at Innenriksdepartementets helseavdelings arkiver ikke inneholder mer enn et par antydninger om at eutanasilover ble vurdert. Vi vet imidlertid fra andre kilder at så skjedde.

Den konspiratoriske tanke melder seg da: Har noen fjernet materiale, fortrinnsvis fra Befolkningskontorets arkiver, som kunne vært avslørende for direktoratets ledelse $i$ en eventuell etterforskning etter krigen? En HV-soldat på vakt utenfor Medisinaldirektoratets lokaler noterer 8. mai 1945 at en kvinne og to menn går inn i lokalene, blir der en times tid og går igjen (9). I landssvikdommen (10) finnes et avhør av sjefen for legekontoret, Olaf Lundemo (1883-1959). Han sier: «Fru Sigrid Mohn kom den 8/5 -45 til Helsedirektoratet og hentet en masse papirer som bl. a. tilhørte befolkningskontoret. En del folk, antagelig fra Statspolitiet, gikk inn i en bil og kjørte bort sammen med fru Mohn.» Sigrid Mohn var Befolkningskontorets siste sjef.

I de samme domspapirer finnes et annet avhør (fra 1946), der ekspedisjonssjef Theodor Gerhard Thorsen (1878-1958) sier: «Den alminnelige mening i Helsedirektoratet (som Medisinaldirektoratet da var omdøpt til) er for øvrig den at siktede (her Østrem) har fjernet mange dokumenter derfra, for å skjule saker som kunde hatt betydning for etterforskningen.» 


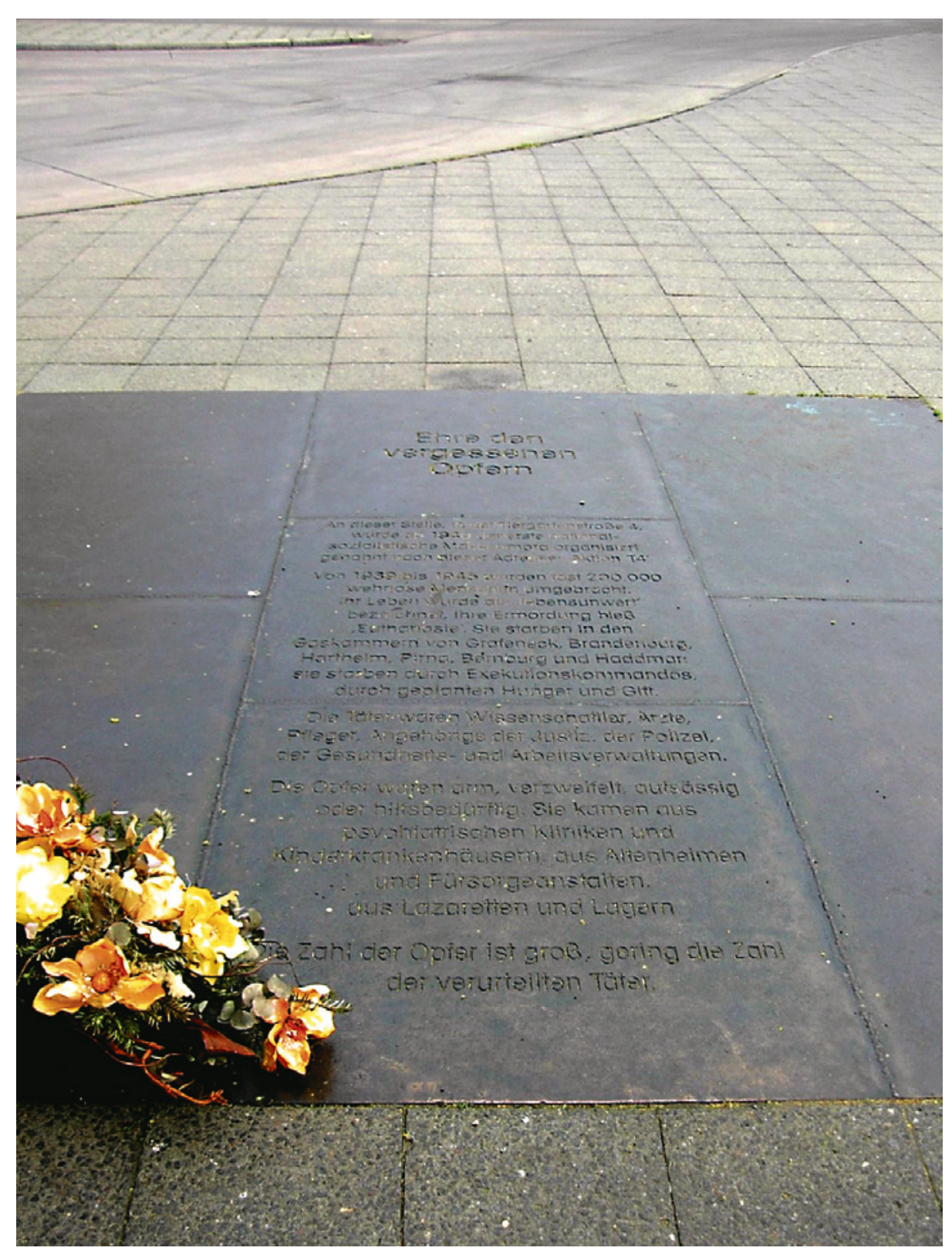

Plakett til minne om ofrene for «Aktion T4» på fortauet foran Tiergartenstrasse 4 i Berlin. Foto: Adam Carr

I Medisinaldirektoratets arkiver finnes altså lite som kan belyse ledelsens holdninger til et eutanasiprogram i Norge. Likevel vet vi at høringsbrev om saken ble sendt og svar samlet inn. Disse dokumentene finnes i eksterne arkiver, for eksempel asylenes, og gode oversikter over saksgangen er tilgjengelige (11-14).

\section{Avlivning eller sterilisering}

Det første initiativet til et eutanasiprogram ser ut til å være en artikkel i Moss Avis 21. februar $1942(11,12)$. Der redegjør fylkesføreren, økonomen Hans E Jacobsen, for de store utgiftene Østfold har til sinnssykebehandling. Han angir at det blir lite igjen til dem som er kortvarig syke. Han argumente- «meningsløst at samfunnet søker å holde liv i disse ulykkelige eksistenser», spesielt «når verdens beste og kraftigste ungdom stuper i hundretusener». Han summerer opp sine forslag og argumenter slik: «Ved å innføre en sådan ordning (avlive sinnssyke) oppnår man at: 1. disse pasienter befries for en meningsløs og ofte smertefull tilværelse 2. de pårørende befries for megen sorg 3. samfunnet spares for meget betydelige utgifter 4 . at det blir bedre plass i asylene til behandling av pasienter som gir håp om helbredelse.»

Langes argumenter er svært typiske for eutanasitilhengerne: Det fremstilles som om «barmhjertighet» er viktigste argument, mens det meget raskt blir klart at økonomi og bedre plass i behandlingsinstitusjonene er det vesentlige. Skyggene av denne argumentasjonen følger også eutanasidebatten inn $i$ văr tid $(4,15)$.

Medisinaldirektør Østrem sendte forslaget fra Christopher Lange uten følgeskriv til høring hos fylkesførerne og til sinnssykehusene (11). Fylkesfører Halvor Hektoen i Hedmark påpekte at han hadde oversendt et tilsvarende forslag tidligere etter brev fra fylkesføreren i Østfold, Hans Jacobsen. Hektoen var prinsipielt for forslaget om avlivning av sinnslidende, men trodde at opinionen lettere ville akseptere et intensivt steriliseringsprogram, selv om dette ville ta lengre tid og var mer kostbart (11). Fylkesføreren i Aust-Agder, Hans H. Pettersen, var helt enig med Lange, som også fikk støtte av fylkesføreren i Telemark (11).

Holdningen hos de nazistiske legene Hva mente så de legene som ble spurt? Fylkeslegen i Vestfold, Fredrik Gustav Hansen (1882-1966), og fylkeslegen i Aust-Agder, Leif Bergh Smith (1894-1978), var enige $i$ at eutanasi burde innføres (11). Smith ville til og med utvide ordningen - han ville avlive ikke bare «kroniske, uhelbredelige, dypt sløvede sinnssyke», men også «idioter». Resten av de nazistiske fylkeslegene var enten unnfallende eller imot. Alle overlegene ved asylene (de var ikke NS-medlemmer) var sterkt imot (11).

Vi har da heller ingen indikasjoner på at det ble foretatt avliving av kronisk syke psykiatriske pasienter i Norge under okkupasjonen. Forslagsstilleren Chr. Lange sier etter å ha sett motinnleggene fra legene: (Svarene) «... har ikke på noen måte rokket ved mitt syn i dette spørsmål. Etter min mening bør man gå til aksjon jo før jo heller».

Lange hadde opprinnelig foreslått at to leger skulle utrede hans forslag. Han sier at han var «bekjent med at de har et sunt og realistisk syn på dette spørsmål» (11). De to legene han foreslo, var ovenfornevnte Fredrik G. Hansen, fylkeslege i Vestfold 
og siste formann i Legeforbundet, og Egil Rian (1904-82), overlege ved Reitgjerdet sykehus og første sjef for Sinnshygienekontoret i Medisinaldirektoratet etter «nyordningen».

Hansen var altså en entusiastisk tilhenger av eutanasi etter tysk mønster (11). Rian støttet ikke forslaget, men ga sitt bidrag ved å demonstrere «problemets» størrelse (9): Nesten $10 \%$ av landets befolkning var etter hans mening «mindreverdige». Selv om han altså ikke støttet avlivning, var han for utvidet adgang til sterilisering av de $10 \%$ «mindreverdige». Disse var, ifølge Rian, «14 000 åndssvake, 25000 sinnssyke, 6000 epileptikere, 3000 arvelig døve og blinde, 280000 asosiale psykopater og sinker».

Sjefen for Sinnshygienekontoret etter Rian, psykiateren Leif Melsom (1892-1968) (som ikke ble anbefalt av Lange), var derimot meget klar. Hans oppfatning kan oppsummeres slik (16): «Forslaget strider mot kristne grunnverdier. Slik aktivitet er imot lege-etikken, legene vil betakke seg for oppgaven. Forslaget om eutanasi av psykiatriske pasienter er taktisk uheldig fordi den norske opinionen i enda større grad vil vende seg mot nasjonalsosialismen.» Melsom anga at han ville fratre sin stilling hvis en lov om dette ble innført.

Medisinaldirektoratet hadde altså denne saken til vurdering, men i direktoratets arkiver finnes få bilag som viser hva man gjorde eller tenkte. Ute i fylkene og på asylene finnes det brev som viser at saken ble grundig overveid (11). Til fylkesfører Hans Jacobsen (som etterlyser handling) skriver medisinaldirektør Østrem: «... et lovforslag om retten til drap er svært radikalt. (...) Dette er en viktig sak, ønskelig med en forandring. ... uhyre delikat tema ... krever samvittighetsfull overveielse.» Og til slutt: «Saken er moden for løsning. Helseavdelingen har sin fulle oppmerksomhet henvendt på spørsmålet. Krigens nødvendighet kan føre fram til en løsning av problemet» (9).
Dette utsagnet fra Østrem tyder på at han ikke var helt avvisende til forslaget om drap av sinnslidende. Det var imidlertid andre NSleger. Få leger var medlemmer av NS før april 1940 (ti?), noen flere i 1945 (133?) (9, 11). Få støttet forslaget om å innføre eutanasi, de fleste var tause eller unnvikende. Vi vet ikke hva profilerte NS-leger, som professor i farmakologi Klaus Hansen (1895-1971), prosektor i anatomi og sekretær i Legeforbundet Konrad Adolf Wagner (1900-56) eller Befolkningskontoret første sjef Arne Høygaard (1906-81) mente i eutanasisaken. Men Leif Melsoms brev til Medisinaldirektøren tyder på at han har diskutert saken med politiske meningsfeller blant legene og at konklusjonen er klart imot eutanasi (16).

\section{Konklusjoner}

Der er fristende å trekke noen konklusjoner på bakgrunn av det materialet som her er referert.

Innenriksdepartementets helseavdeling, Medisinaldirektoratet, foreslo aldri formelt å innføre eutanasi etter tysk T4-mønster i Norge. Medisinaldirektørens holdning til eutanasi er noe uklar. Biskop Eidsvig har likevel ikke rett i sin påstand $\mathrm{i}$ Tidsskriftet (1), slik den er sitert innledningsvis i denne artikkelen.

Forslagene om å innføre drap på psykiatriske pasienter kom i Norge fra medlemmer av NS-hierarkiet som ikke var leger. Dette i motsetning til hva tilfellet var i Tyskland, der legene var pådriverne.

Det kan se ut som om profilerte NS-leger var motstandere av eutanasiforslaget i Norge. Særlig sjefen for Sinnshygienekontoret, Leif Melsom, har mye av æren for at forslaget ble stoppet.

\section{Ragnar Stien (f. 1938)}

er pensjonert nevrolog.

Forfatter har fylt ut ICMJE-skjemaet og oppgir ingen interessekonflikter.
Litteratur

1. Eidsvig B. Eutanasi og spøkelsene fra fortiden. Tidsskr Nor Legeforen 2009: 129: 720.

2. Binding K, Hoche A. Die Freigabe der Vernichtung lebensunwerten Lebens. Ihr Mass und ihre Form. Leipzig: Meiner Verlag, 1920.

3. Roelcke V Medicine during the Nazi period: Historic facts and some implications for teaching medical ethics and professionalism. I: Rubenfeld S, red. Medicine after the Holocaust. From master race to the human genome and beyond. London: Palgrave McMillan, 2010: 17-28.

4. Roelcke V, Topp S, Lepicard E. red. Silence, scapegoats and self-reflection. The shadow of Nazi medical crimes on medicine and bioethics. Göttingen: V\&R Unipress, 2014

5. von Boeltzingsloeven I. Starvation in French mental hospitals under Nazi occupation: misinterpretations and instrumentalization since 1945. I: Roelcke V, Topp S, Lepicard E, red. Silence, scapegoats and self-reflection. The shadow of Nazi medical crimes on medicine and bioethics. Göttingen: V\&R Unipress, 2014: 231-42.

6. Klaveness T. Oslo kommunale sykehus i krigens tegn. Oslo: Cammermeyer, 1947: 81-2.

7. Thorleif Østrems privatarkiv 1948-72. OSL $13 F$ 35706/1 L0015. Riksarkivet.

8. Stien R, Aaarli JA. Hjernens leger - historien om de første norske nevrologene. Oslo: Den norske nevrolitterære klubbs forlag, 2012.

9. Innenriksdepartementets arkiv 1938-46. Helseavdelingen. H1-7. L0199. Oslo: Riksarkivet.

10. Landssvikdom nr. 4259, Thorleif Østrem. Landsvikarkivet, Riksarkivet. Hyllenr 1B00422. Riksarkivet.

11. Haave P. Ambisjon og handling. Sanderud sykehus og norsk psykiatri i et historisk perspektiv. Oslo: Unipub, 2008

12. Gogstad AC. Helse og hakekors. Bergen: Alma Mater, 1991.

13. Gogstad AC. Slange og sverd. Bergen: Alma Mater, 1995

14. Professor Anders Chr. Gogstads privatarkiv. Riks arkivet.

15. van der Sluis I. Het recht om groosmoeder te doden. Amsterdam: Saint Jaques, 1977.

16. Melsom L. P.M. til Medisinaldirektøren fra Sinnshygienekontoret. Ad fylkesmann Chr Langes brev av 21. november 1944 til Medisinaldirektøren om uhelbredelige sinnssyke. H4 L0199. Riksarkivet.

Mottatt 5.3. 2015, første revisjon innsendt 10.6. 2015, godkjent 5.8. 2015. Redaktør: Kari Tveito. 